07

\title{
Лазерная генерация в микродисках с активной областью на основе решеточно-согласованных InP/AllnAs наноструктур
}

\author{
() Д.В. Лебедев, ${ }^{1}$ А.М. Минтаиров, ${ }^{1,2}$ А.С. Власов, ${ }^{1}$ В.Ю. Давыдов, ${ }^{1}$ М.М. Кулагина, ${ }^{1}$ C.И. Трошков, ${ }^{1}$ \\ A.A. Богданов, ${ }^{1,3}$ A.H. Смирнов, ${ }^{1}$ A. Gocalinska, ${ }^{4}$ G. Juska, ${ }^{4}$ E. Pelucchi, ${ }^{4}$ J. Kapaldo, ${ }^{2}$ \\ S. Rouvimov, ${ }^{2}$ J.L. Merz ${ }^{2}$ \\ ${ }^{1}$ Физико-технический институт им. А.Ф. Иофрфе РАН, \\ 194021 Санкт-Петербург, Россия \\ ${ }^{2}$ University of Notre Dame, \\ 46556 Notre Dame, USA \\ ${ }^{3}$ Университет ИТМО, \\ 197101 Санкт-Петербург, Россия \\ ${ }^{4}$ Tyndall National Institute, \\ Cork, Ireland \\ e-mail: lebedev.dmitri@mail.ioffe.ru
}

(Поступило в Редакцию 10 мая 2016 г.)

\begin{abstract}
Исследованы излучающие свойства ненапряженных квантово-размерных наноструктур InP/AlInAs и лазерная генерация этих наноструктур в микродисковых резонаторах, сформированных мокрым травлением. Для исходных структур было обнаружено, что их излучение обусловлено квантово-размерными InP-островками с диаметром 50-300 nm. Для микродисков мы наблюдали моды шепчущей галереи при температурах ниже $160 \mathrm{~K}$. Эксперименты по измерению зависимости интенсивности фотолюминесценции мод микрорезонатора от мощности накачки, проведенные при температуре жидкого гелия, позволили установить величину порога лазерной генерации, который составил $50 \mathrm{~W} / \mathrm{cm}^{2}$. Полуширина лазерной линии при мощностях, превышающих пороговые, составляла $0.06 \mathrm{~nm}$, что соответствует добротности 15000 .
\end{abstract}

DOI: 10.21883/JTF.2017.07.44680.1881

\section{Введение}

В работе [1] было обнаружено, что при определенных условиях роста осаждение $1-8 \mathrm{~nm} \operatorname{InP}$ на слой AlInAs толщиной $100 \mathrm{~nm}$, выращенный на (100) грани ориентированной InP-подложки, при помощи металлоорганической эпитаксии из газовой фазы не приводит к послойному росту InP, а приводит к собиранию осажденного материала в островки и нити. Отработка воспроизводимости режимов роста позволила получать новый тип низкоразмерных наноструктур с низкой плотностью $\sim 10^{8} \mathrm{~cm}^{-2}$, называемый также агрегационными квантовыми точками, несмотря на их широкое распределение по латеральному размеру $\sim 20-250 \mathrm{~nm}$. Образование таких наноструктур предположительно обусловлено локальными напряжениями, возникающими вследствие неравномерного распределения атомов твердого pacтвора AlInAs. При этом было установлено, что критическое влияние на морфологию поверхности и вид наноструктур оказывает грань роста и разориентация подложки [1,2]. Также следует особо отметить, что образование именно островков происходит в диапазоне температур 565-630 ${ }^{\circ} \mathrm{C}$, причем было обнаружено влияние температуры роста на плотность и высоту получаемых наноструктур. Особенностью полученной наноструктуры является согласованность параметров кристаллической решетки материала точки и подложки. При этом, несмотря на то что образование каждой отдельной точ- ки обусловлено локальными напряжениями, в среднем сама наноструктура является ненапряженной. Поскольку гетеропереход InP/AlInAs относится ко второму типу [3], то использование таких наноструктур позволяет создавать ограничивающий потенциал для электронов в области точки, при этом рекомбинация сопровождается излучением в области ближнего ИК диапазона.

В силу большого латерального размера такие квантовые островки представляют определенный интерес при использовании их в качестве активной области лазеров на основе микродисковых резонаторов. Преимущества использования таких резонаторов в лазерах обусловлены их малым размером, высокой добротностью, а также возможностью достижения низкопороговой генерации $[4,5]$, что является следствием существования в них собственных мод шепчущей галереи (МШГ).

Известно, что порог лазерной генерации для микрорезонаторов [6] определяется такими факторами, как добротность и вклад спонтанного излучения в лазерную моду, при этом в случае использования в качестве активной среды массива квантовых точек важную роль играет геометрия их расположения $[7,8]$. Модификация спонтанного излучения в резонаторе характеризуется величиной коэффициента Парселла, а его максимальные значения достигаются помещением точечного излучателя в положение максимума поля резонансной моды. Так, можно ожидать, что для резонаторов, активная область которых содержит квантовые точки большого 
размера, будет наблюдаться низкий порог генерации в силу большего перекрытия с полем лазерной МШГ. Проведенные эксперименты по исследованию микродисков с самоорганизованными InP/GaInP квантовыми точками, имеющими большой размер $(\sim 100 \mathrm{~nm})$ и малую плотность $\left(\sim 10^{9} \mathrm{~cm}^{-2}\right)$, подтверждают данную гипотезу [9], порог лазерной генерации, достигнутый на этом объекте, является наименьшим, и по абсолютной величине составляет $\sim 1 \mathrm{nW}$ (при температуре $15 \mathrm{~K}$ ).

В настоящей работе мы впервые исследовали излучающие свойства квантово-размерных InP/AlInAsструктур, подобных полученным в работе [1], характеризуемых большим латеральным размером и малой плотностью. А также исследовали их использование в качестве активной области микродисковых резонаторов.

\section{1. Экспериментальная часть}

Образцы с квантовыми наноструктурами были выращены на InP (100) полуизолирующей подложке при помощи металлоорганической газофазной эпитаксии. Для образца I на подложку осаждали $100 \mathrm{~nm}$ буферного слоя $\mathrm{InP}$, за которым следовал $140 \mathrm{~nm}$ слой $\mathrm{Al}_{0.48} \mathrm{In}_{0.52} \mathrm{As}$, затем осаждали $0.75-1 \mathrm{~nm}$ InP-слой, который был закрыт также слоем $140 \mathrm{~nm} \mathrm{Al} \mathrm{Al}_{0.48} \mathrm{In}_{0.52}$ As. Слои AlInAs служили волноводом. Образец II отличается тем, что нижний слой AlInAs был легирован $n$-типом примеси на расстоянии $20 \mathrm{~nm}$ от слоя наноструктур. Толщина области ввода примеси составляла также $20 \mathrm{~nm}$. Детальное описание процесса роста описано в работе [1]. Температура роста для AlInAs-слоев составляла $600^{\circ} \mathrm{C}$, а для InP-наноструктур $630^{\circ} \mathrm{C}$. Соотношение V/III 110 и 180 соответственно. Согласно данным просвечивающей электронной микроскопии (ПЭМ) (рис. 1), осажденный InP не образует ровный слой, а собирается в островки с широким распределением по диаметру $(50-300 \mathrm{~nm})$, с высотой таких островков $2.3 \mathrm{~nm}$. Данные ПЭМ были получены с использованием микроскопа FEI Titan 80-300, ускоряющее напряжение составляло $300 \mathrm{kV}$, срезы образцов готовили с использованием установки FEI Helious Dual Beam.

Из полученных структур были сформированы микродиски с диаметрами $3-3.5 \mu \mathrm{m}$ при помощи оптической фотолитографии и химического травления с использованием $\mathrm{HCl}, \mathrm{H}_{3} \mathrm{PO}_{4}$ и $\mathrm{CH}_{3} \mathrm{COOH}$. Изображение микродиска с диаметром $3.2 \mu \mathrm{m}$, полученное с использованием сканирующего электронного микроскопа (СЭМ), представлено на рис. 2.

Спектры фотолюминесценции (ФЛ) были измерены при помощи монохроматора МДР-23, в качестве детектора использовали ФЭУ-62, возбуждение проводили твердотельным лазером $(\lambda=532 \mathrm{~nm})$. Эксперименты по определению порога лазерной генерации и эксперименты с временным разрешением проводились с помощью стандартной системы микрофотолюминесценции, описанной в [10], при импульсном возбуждении лазером

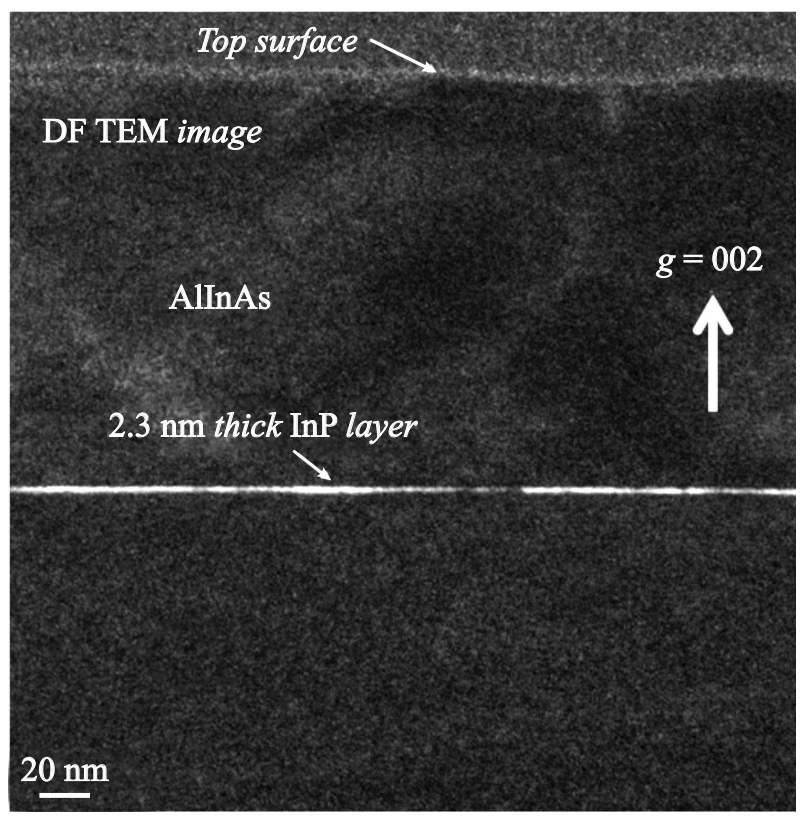

Рис. 1. Темнопольное ПЭМ изображение исследуемой структуры (образец II). Светлые участки соответствуют InP.

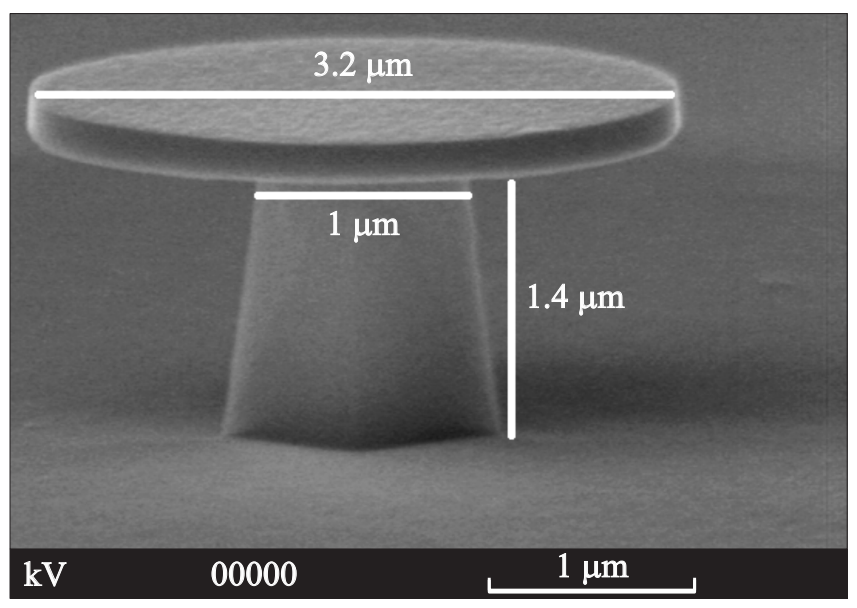

Рис. 2. СЭМ изображение микродиска, полученного мокрым травлением.

с длиной волны $635 \mathrm{~nm}$ и частотой $10 \mathrm{MHz}$. Мощность излучения на образце контролировалась путем использования нейтральных фильтров.

\section{2. Экспериментальные результаты и их обсуждение}

\section{1. ФЛ исходной структуры}

Спектр ФЛ исходной структуры (образец I) при плотности мощности накачки $10 \mathrm{~W} / \mathrm{cm}^{2}$ при $77 \mathrm{~K}$ приведен на рис. 3. Наблюдали две спектральные полосы, соответствующие рекомбинации на гетеропереходе AlInAs/InPбуферный слой $(\sim 1 \mu \mathrm{m}, 1.24 \mathrm{eV})$ и рекомбинации в 


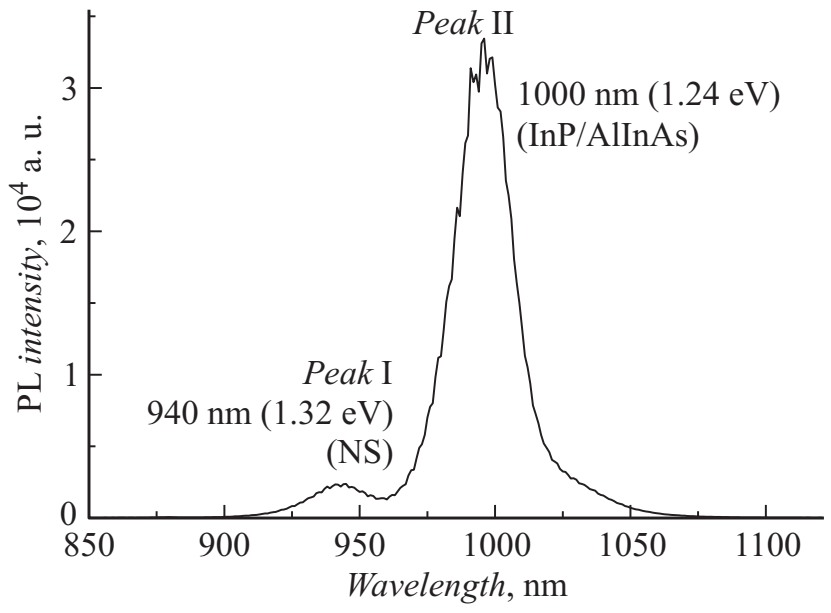

Рис. 3. ФЛ исходной структуры при плотности мощности $\sim 10 \mathrm{~W} / \mathrm{cm}^{2}$.

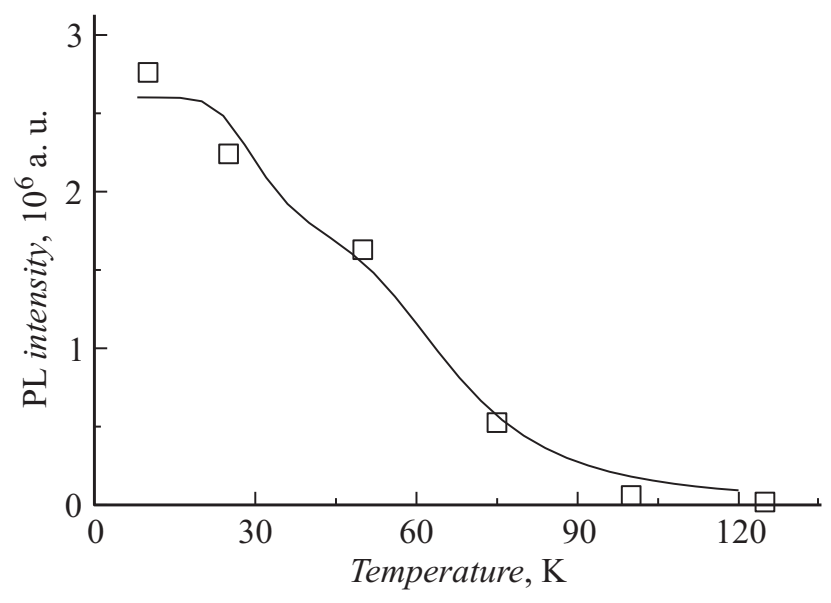

Рис. 4. Зависимость интегральной интенсивности ФЛ полосы наноструктур от температуры. Приведена аппроксимация этой зависимости с использованием выражения (1) с учетом двух центров безызлучательной рекомбинации.

области наноструктур ( $940 \mathrm{~nm}, 1.32 \mathrm{eV})$. Из литературных данных известно, что технология осаждения InP на AlInAs (и наоборот) существенно влияет на положение полос ФЛ - положение полосы от гетероперехода варьирует в диапазоне $1.1-1.3 \mathrm{eV}[3,11,12]$. В большинстве случаев такое поведение определяется неоднородностью приграничного слоя по составу, приводящее к образованию InAs-квантовой ямы на границе, при этом рекомбинацию на таком гетеропереходе относят к смешанному типу I-II. Поскольку для наших образцов увеличение мощности накачки приводит к смещению полосы при $1 \mu \mathrm{m}$ в сторону более коротких длин волн, то это подтверждает наше предположение о том, что данная полоса относится к рекомбинации на гетеропереходе II типа, а не в наноструктурах. Соавторами работы при помощи экспериментов по селективному химическому травлению [1] была определена неоднород- ность отдельных островков по составу. Было выявлено, что середина InР-островков включает в себя примесь мышьяка. Различие в положении обеих полос составляет примерно $80 \mathrm{meV}$, что вероятней всего отражает величину размерного квантования в наноструктурах.

Увеличение температуры до $160 \mathrm{~K}$ приводит к резкому уменьшению интенсивности ФЛ полосы, соответствующей наноструктурам, тогда как другие полосы сохраняются. Зависимость интегральной интенсивности ФЛ полосы наноструктур от температуры, измеренная для диапазона $10-160 \mathrm{~K}$, приведена на рис. 4. Для гетероструктур с низкой плотностью дефектов такая зависимость описывается феноменологическим выражением [13]:

$$
I_{P L}=\frac{I_{0}}{1+\sum \frac{\tau_{0}}{\tau_{i}} \exp \left(\frac{-E_{a i}}{k T}\right)},
$$

где $I_{0}$ - это интенсивность ФЛ при $T=0 \mathrm{~K}, \tau_{i}$ - время выхода экситона на і-й безызлучательный центр, $\tau_{0}$ излучательное время жизни экситона, $E_{a i}-$ энергия активации перехода носителя на і-й безызлучательный центр и $k-$ постоянная Больцмана. Нами было определено два центра безызлучательной рекомбинации с энергиями активации 0.01 и $0.08 \mathrm{eV}$. Природа центров не ясна, но мы предполагаем, что первый центр может быть связан с дефектами слоя AlInAs, тогда как второй, по-видимому, обусловлен уходом дырок из области наноструктур.

\section{2. Микрофотолюминесценция микродисков}

При низкой $(10-160 \mathrm{~K})$ температуре мы наблюдали интенсивные (соотношение интенсивностей ФЛ $I_{W G M} / I_{\text {nano }} \sim 2-3$ ) спектральные линии, соответствующие МШГ резонатора, которые образуются за счет распространения электромагнитной волны вдоль стенки резонатора. Расстояние между соседними максимумами мод определяется частотой поля, размерами и материалами резонатора. Однако все эти параметры можно заменить эффективным показателем преломления [14].

Для полученных дисков с использованием программного пакета COMSOL Multiphysics были определены азимутальный и радиальный индексы мод шепчущей галереи. Анализ модового состава проводился с помощью метода конечных элементов путем решения двумерного уравнения Гельмгольца в цилиндрических координатах (осевая симметрия задачи позволяет выбрать для мод угловую зависимость в форме $\exp (\operatorname{im} \varphi)$, где $m$ - это радиальное число, благодаря чему можно свести трехмерную задачу к двумерной $[15,16])$. Сопоставление результатов компьютерного моделирования спектров микродисков диаметром 3-3.5 $\mu \mathrm{m}$ с экспериментальными спектрами показало, что лазерная генерация осуществляется на квази-ТЕ модах первого и второго радиального порядков.

Для полученных микродисков в температурном интервале 10-90К было обнаружено, что при увеличении мощности накачки от 10 до $400 \mathrm{~W} / \mathrm{cm}^{2}$ происходит 


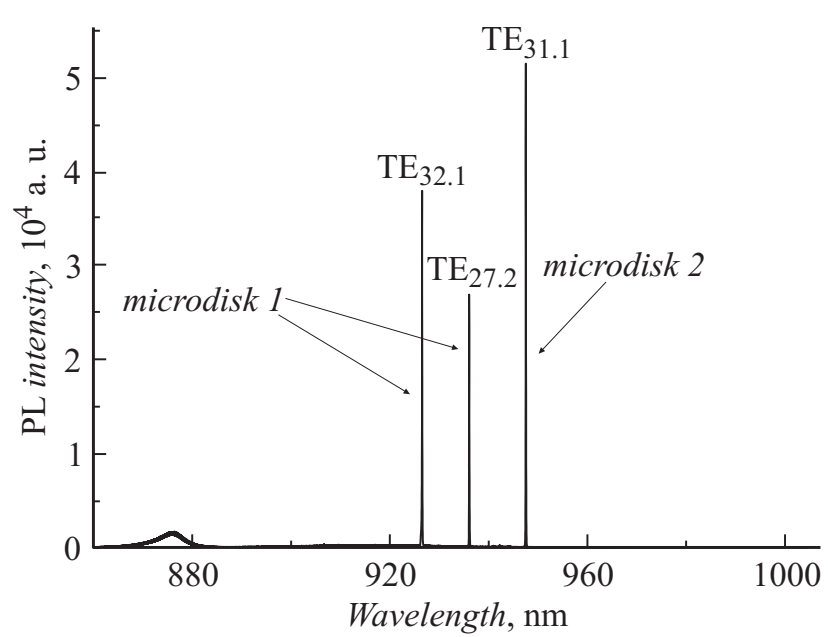

Рис. 5. Спектр микрофотолюминесценции двух микродисков в режиме лазерной генерации.

резкое возрастание интенсивности отдельной моды или мод, указывающее на возникновение лазерной генерации. Спектры излучения в режиме генерации при $10 \mathrm{~K}$ для двух микродисков (образец II), имеющих диаметр $3.5 \mu \mathrm{m}$, показаны на рис. 5, из которого видно, что на исследуемых микродисках возможно получение как одномодовой, так и двумодовой генерации. Полуширина мод в режиме генерации составила $0.06 \mathrm{~nm}$, что соответствует добротности $Q \sim E / \Delta E \approx 15000$. Из зависимостей интенсивности фотолюминесценции от мощности накачки был определен порог лазерной генерации, который составил $50 \mathrm{~W} / \mathrm{cm}^{2}$. Известно, что в случае микрорезонаторов такая зависимость описывается следующим выражением [8,17], связывающим число фотонов $p$ с током накачки $I$ :

$$
I(p)=A\left[\frac{p}{1+p}(1+\xi)(1+\beta p)-\xi \beta p\right] .
$$

Здесь параметр $A=h \omega \gamma / \delta \beta$, где $\omega$ - частота моды, $\gamma$ - скорость ухода фотонов из резонатора, а $\delta$ эффективность преобразования фотонов. В случае оптической накачки I соответствует мощности накачки, а интенсивность ФЛ пропорциональна $p$. Безразмерный параметр $\xi=N_{0} \beta V / \gamma \tau_{s p}$, где $N_{0}-$ концентрация носителей при просветлении активной области, $V$ объем активной области, а $\tau_{s p}-$ время жизни спонтанного излучения. Поскольку для микрорезонаторов характерен высокий вклад спонтанного излучения в лазерную моду $\beta$, то данная зависимость носит сглаженный характер [6], что было подробно исследовано и промоделировано в работе [18].

Аппроксимация экспериментальной зависимости с использованием выражения (2) позволяет определить параметр $\beta$. Однако оценка данного вклада исходя только из формы зависимости выходной мощности от входной является неточной, поскольку на ее форму также оказывает существенное влияние величина $N_{0}$.
Согласно теоретическим расчетам скорости излучения в моду микродискового резонатора, величина вклада спонтанного излучения для микродисков приближается к 30\% при условии близости радиуса диска к длине волны [14]. В то же время, согласно анализу экспериментальных зависимостей, рядом авторов были получены следующие значения $\beta$ для МШГ: $0.02-0.85$ в $\mathrm{ZnSe}$ микродисках с CdSe квантовыми точками (КT) [19]; 0.61 в GaAsAlGaAs микропилларах с InAs KT [20]; 0.14 в $\mathrm{GaN}$ микродисках с InGaN квантовой ямой (КЯ) [21]; 0.1 в GaInAsP микродисках [22]; 0.09 в (Al,Ga)As/GaAs микродисках c InAs KT [17]. Наилучшая аппроксимация экспериментальной зависимости (рис. 6) была получена при значениях $\beta=0.23$ и $\xi=8$.

Также нами были проведены эксперименты по ФЛ с временным разрешением, позволившие установить, что время жизни спонтанного излучения в моду резонатора в 1.4 раза меньше времени жизни излучения в свободное пространство. Согласно работе [23], вклад спонтанного излучения может быть оценен из выражения $\beta=1-\tau_{\text {cav }} / \tau_{\text {free }}$, где $\tau_{\text {cav }}$ и $\tau_{\text {free }}-$ время жизни излучения в моду резонатора и свободное пространство соответственно. Исходя из этого величина $\beta$ была также оценена, она составила 0.29 , что находится в согласии со значением $\beta$, полученного из аппроксимации зависимости интенсивности от мощности накачки.

Сравним полученные результаты с результатами работы [24]. Сравниваемые структуры представлены разными материалами и различной технологией получения квантовых точек. В случае работы [24] использовали GaInPмикродиски с введенными InP КT, имеющими размер $4-5 \mathrm{~nm}$ и плотностью $1.5 \cdot 10^{10} \mathrm{~cm}^{-2}$. Тогда как условия получения микродисковых резонаторов являются идентичными (мокрое травление, оптическая литография). Также близкими являются условия накачки. Из сравнения экспериментальных данных видно, что пороговая плотность мощности $\left(100-200 \mathrm{~W} / \mathrm{cm}^{2}\right)$, определенная в

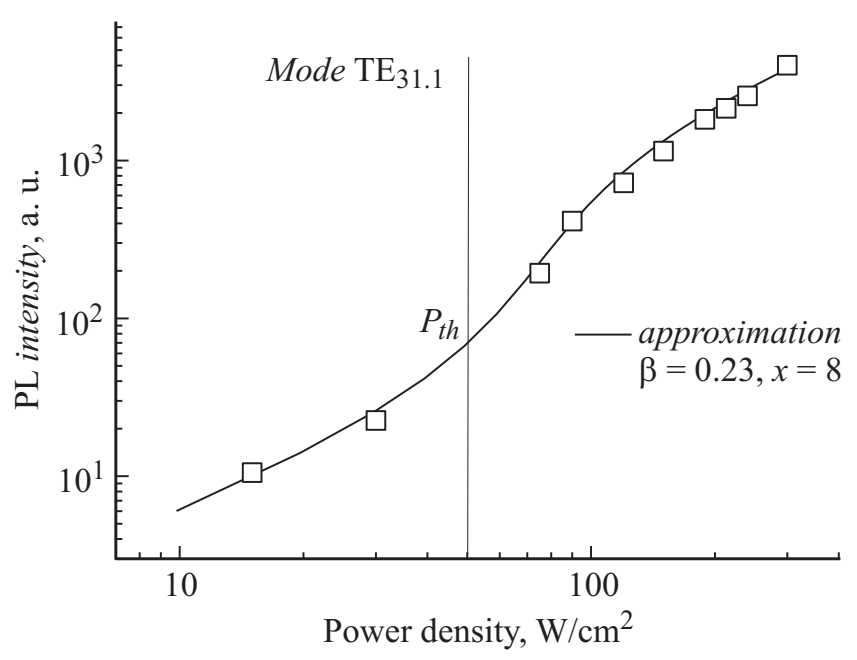

Рис. 6. Зависимость интенсивности ФЛ от мощности оптической накачки. Приведена аппроксимация этой зависимости с использованием выражения (2). 
работе [24] немного выше, тогда как вклад спонтанного излучения $(\beta=0.195)$ немного меньше, чем в нашей, однако добротность мод $(Q=35800)$ существенно выше.

\section{3. Заключение}

Показано, что спектр ФЛ исследуемых InP/AlInAs наноструктур лежит в области ближнего ИК-диапазона $(900-1000 \mathrm{~nm})$, что позволяет их использовать в качестве активной области микродисковых резонаторов с диаметром $\sim 3 \mu \mathrm{m}$. Исследуемые микродиски демонстрируют низкий порог лазерной генерации $\left(\sim 50 \mathrm{~W} / \mathrm{cm}^{2}\right)$ при температуре $10 \mathrm{~K}$, которая наблюдается на одной или двух модах шепчущей галереи с добротностью 15000 . При этом оцененный вклад спонтанного излучения в лазерную моду $\beta$ составляет 0.23 .

Д.В. Лебедев и А.М. Минтаиров благодарит Министерство образования и науки Российской Федерации (контракт № 14.Z50.31.0021 от 7 апреля 2014 г.). А.А. Богданов благодарит за поддержку фонд РФФИ (16-37-600-64) и грант президента РФ (МК-6462.2016.2). E. Pelucchi, A. Gocalinska и G. Juska благодарят Science Foundation Ireland (Grant Nos. 12/RC/2276 и 10/IN.1/I3000).

\section{Список литературы}

[1] Gocalinska A., Manganaro M., Juska G., Dimastrodonato V., Thomas K., Joyce B.A., Zhang J., Vvedensky D.D., Pelucchi E. // Appl. Phys. Lett. 2014. Vol. 104. N 14. P. 141606.

[2] Gocalinska A., Manganaro M., Pelucchi E., Vvedensky D.D. // Phys. Rev. B. 2012. Vol. 86. N 16. P. 165307.

[3] Abraham P., Garcia Perez M.A., Benyattou T., Guillot G., Sacilotti M., Letartre X. // Semicond. Sci. Technol. 1995. Vol. 10. N 12. P. 1585-1594.

[4] Крыжсановская Н.В., Жуков А.Е., Надточий А.М., Словинский И.А., Максимов М.В., Кулагина М.М., Савельев А.В., Аракчеева Е.М., Задиранов Ю.М., Трошков С.И., Липовский А.А. // ФТП. 2012. Т. 46. Вып. 8. C. 1063-1066.

[5] Жуков А.Е., Крыжсановская Н.В., Максимов М.В., Липовский А.А., Савельев А.В., Богданов А.А., Шостак И.И., Моисеев Э.И., Карпов Д.В., Laukkanen J., Tommila J. // ФТП. 2014. Т. 48. Вып. 12. С. 1666-1670.

[6] Yamamoto Y., Machida S., Bjork G. // Phys. Rev. A. 1991. Vol. 44. N 1. P. 657-668.

[7] Reitzenstein S., Bockler C., Bazhenov A., Gorbunov A., Loffler A., Kamp M., Kulakovskii V.D., Forchel A. // Opt. expres. 2008. Vol. 16. N 7. P. 4849-4857.

[8] Reitzenstein S., Bazhenov A., Gorbunov A., Hofmann C., Munch S., Loffler A., Kamp M., Reithmaier J.P., Kulakovskii V.D., Forchel A. // Appl. Phys. Lett. 2006. Vol. 89. N 5. P. 051107.

[9] Chu Y., Mintairov A.M., He Y., Merz J.L., Kalugnyy N.A., Lantratov V.M., Mintairov S.A. // Phys. Status Solidi C. 2011. Vol. 8. N 2. P. 325-327.
[10] Juska G., Murray E., Dimastrodonato V., Chung T.H., Moroni S.T., Gocalinska A., Pelucchi E. // J. Appl. Phys. 2015. Vol. 117. N 13. P. 134302.

[11] V. Duez V., Vanbesien O., Lippens D., Vignaud D., Wallart X., Mollot F. // J. Appl. Phys. 1999. Vol. 85. N 4. P. 2202-2206.

[12] Pocas L.C., Duarte J.L., Dias I.F.L., Laureto E., Lourenco S.A., Toginho Filho D.O., Meneses E.A., Mazzaro I., Harmand J.C. // J. Appl. Phys. 2002. Vol. 91. N 11. P. 8999 9004.

[13] Lourenco S.A., Dias I.F.L., Pocas L.C., Duarte J.L., De Oliveira J.B.B., Harmand J.C. // J. Appl. Phys. 2003. Vol. 93. N 8. P. 4475-4479.

[14] Chin M.K., Chu D.Y., Ho S.T. // J. Appl. Phys. 1993. Vol. 75. N 7. P. $3302-3307$.

[15] Городецкий М. Оптические микрорезонаторы с гигантской добротностью. М.: Физматлит, 2011. 416 с.

[16] Oxborrow M. // IEEE Trans. Microw. Theor. 2007. Vol. 55. N 6. P. $1209-1218$.

[17] Wang W.H., Ghosh S., Mendoza F.M., Li X., Awschalom D.D., Samarth N. // Phys. Rev. B. 2005. Vol. 71. N 15. P. 155306.

[18] Bjork G., Yamamoto Y. // IEEE J. Quant. Elect. 1991. Vol. 27. N 11. P. 2386-2396.

[19] Renner J., Worschech L., Forchel A., Mahapatra S., BrunnerK. // Appl. Phys. Lett. 2006. Vol. 89. N 23. P. 231104

[20] Jones B.D., Oxborrow M., Astratov V.N., Hopkinson M., Tahraoui A., Skolnick M.S., Fox A.M. // Opt. Expres. 2010. Vol. 18. N 21. P. 22578-22592.

[21] Zhang Y., Ma Z., Zhang X., Wang T., Choi Y.W. // Appl. Phys. Lett. 2014. Vol. 104. N 22. P. 221106

[22] Fujita M., Ushigome R., Baba T. // IEEE Photonic. Tech. Lett. 2001. Vol. 13. N 5. P. 403-405.

[23] Solomon C.S., Pelton M., Yamamoto Y. // Phys. Rev. Lett. A. 2001. Vol. 86. N 13. P. 3903-3906.

[24] Witzany M., Rossbach R., Shulz W.-M., Jetter M., Michler P. // Phys. Rev. B. 2011. Vol. 83. N 20. P. 205305. 